Gut, 1986, 27, 486-490

\title{
Acid, pepsin, and mucus secretion in patients with gastric and duodenal ulcer before and after colloidal bismuth subcitrate (De-Nol)
}

\author{
J H BARON, J BARR, J BATTEN, R SIDEBOTHAM, AND J SPENCER \\ From the Department of Surgery, Royal Postgraduate Medical School and Department of Medicine, St \\ Charles Hospital, London
}

SUMMARY Basal and pentagastrin stimulated gastric secretion was measured in seven patients with duodenal, and six with gastric ulcers before and after four weeks' treatment with colloidal bismuth subcitrate (as De-Nol), one tablet four times a day. Each duodenal and all but one of the gastric ulcers healed. After De-Nol there were no significant changes in basal, or pentagastrin stimulated volume, acid output, or primary parietal component. There were marked decreases in basal (duodenal ulcer $-25 \%$; gastric ulcer $-16 \%$ ) and pentagastrin stimulated total pepsin outputs, (duodenal ulcer $-42 \%$, gastric ulcer $-36 \%$ ). There were insignificant decreases in basal output of mucus, but postpentagastrin stimulated mucus output was significantly inhibited $(\mathrm{p}<0.05)$ in patients with duodenal $(-16 \%)$ and with gastric ulcer $(-27 \%)$. The drop in gastric proteolysis after De-Nol is unlikely to be because of the healing of the ulcers and is more likely to be because of the drug. The ulcer healing efficacy of De-Nol may be related to this decline in the proteolytic action of gastric juice, but is unlikely to be because of a quantitative change in mucus, or in acid secretion.

Salts of bismuth have been used to treat gastrointestinal diseases for about 200 years. De-Nol is colloidal bismuth subcitrate (tripotassium dicitratobismuthate, TDB): the liquid and the newer tablets increase the rate of healing of duodenal and gastric ulcers with an efficacy comparable with other antiulcer drugs. The mechanisms of action of bismuth formulations are unclear, and thought to be topical. ${ }^{1}$

It has been stated that De-Nol enhances mucosal resistance by stimulating production of mucus. ${ }^{2}$ The evidence is inconclusive and there have been few studies on the effect of preparations of bismuth salts on production of mucus in the 75 years since the original histochemical studies in dogs using the subnitrate ${ }^{3}$ oxide, and carbonate. ${ }^{4}$ De-Nol, however, appears to increase intracellular levels of neutral mucus glycoprotein during healing of gastric ulcer, ${ }^{5}$ and during healing of duodenal ulcer promotes ultrastructural changes in mucous cells that are compatible with an increased synthesis of mucus glycoprotein. ${ }^{6}$

Address for correspondence: Dr J H Baron. Department of Surgery. RPMS Hammersmith Hospital. London W12 0HS.

Received for publication 16 July 1985
Animal studies ${ }^{7}$ have not shown any clear effect of De-Nol on gastric secretion. There are no extensive data on the effects of treatment with DeNol on basal and maximal acid, and pepsin secretion in patients with gastric and duodenal ulcer. We have therefore measured acid, pepsin, and mucus in patients before and after De-Nol using techniques which take into account problems of gastric emptying and reflux.

\section{Methods}

SUBJECTS

Patients with endoscopically diagnosed peptic ulcer were treated with De-Nol, 1 tablet four times a day for four weeks, and then they were re-endoscoped. There were four men and three women with duodenal ulcer (mean age 49 years, range 28-72) and four men and two women with gastric ulcer (mean age 60 years, range 44-81). One gastric ulcer was in the body of the stomach, three were on the lesser curve of the incisura, one was antral, and one prepyloric. The patients gave informed consent to these studies which were approved by the District Ethics Committees. 
DETERMINATION OF ACID, PEPSIN AND VOLUME Secretion studies ${ }^{8}$ were performed before starting De-Nol and 24 hours after the last dose. Gastric secretion was aspirated continuously and collected in 10 minute fractions for 30 minute basal and for 90 minutes during intravenous infusion of a maximal dose of pentagastrin $(6 \mu \mathrm{g} / \mathrm{kg} / \mathrm{h})$. The volume, $\mathrm{pH}$, titratable acidity (to $\mathrm{pH} 7$ ), sodium concentrations and pepsin activity were measured in each sample. The samples were prediluted 1 in 20 before pepsin was assayed by an auto-analytical method. ${ }^{9}$ Pepsin was inadvertently not measured in one patient with duodenal and in one with gastric ulcer.

Basal and plateau acid outputs were expressed in $\mathrm{mmol} / \mathrm{h}$ by doubling the basal 30 minute output and trebling the plateau output in the highest two consecutive 10 minute outputs during the infusion of pentagastrin. Acid outputs were then corrected for gastroduodenal loss by measurement of the phenol red concentrations in relation to the amount of this marker dye continuously infused into the stomach: duodenal reflux was estimated from the sodium concentration. These concentrations of phenol red do not appreciably interfere with the pepsin assay. ${ }^{9}$ In one patient with duodenal ulcer the infusion was irregular during the basal period so that his uncorrected basal output has been used. The formulae used were those of Hobsley. ${ }^{10} 11$ Basal and stimulated pepsin outputs were calculated similarly and expressed in Anson units/h.

\section{DETERMINATION OF MUCUS}

Gastric mucus is a gel formed when mucus glycoproteins interact in the presence of a solvent system consisting of an aqueous solution of salts. In comparison with other gels gastric mucus has a complex structure because it contains organic molecules other than mucus glycoproteins. These include proteins, lipids, and glycoproteins, which are secreted from cells in the mucosa, or arise by transudation from the mucosal blood supply. A thin layer of gastric mucus normally covers the gastric mucosa. As this protective barrier breaks down, the components of the gel are released into the lumen of the stomach as a part of the gastric secretion. In the present study, therefore, mucus output is represented by the combined weight of protein, lipid, and glycoprotein that accumulates in the gastric juice during the basal and stimulated periods of secretion. The solvent system is treated as non-variable because it accounts for over $99 \%$ of the weight of gastric mucus.

The aqueous solution of salts constituting the solvent system of the mucus, phenol red marker dye and small molecular weight peptides and amino acids (which arise from a limited acid-pepsin pro- teolysis of the mucus during the collection period) are removed from the protein, lipid, and glycoprotein components of the mucus by dialysis and lyophilisation.

\section{EXPERIMENTAL PROCEDURE}

The sample of pooled and neutralised basal or stimulated gastric juice was homogenised to disperse any insoluble mucus, clarified by centrifugation at $2000 \mathrm{~g}$ for 10 minutes, and the volume measured. The juice was concentrated (if necessary) to about $200 \mathrm{ml}$ by evaporation in vacuo at $40^{\circ} \mathrm{C}$, and dialysed for 72 hours against $3 \times 5$ litres of deionised water. The non-dialysable material, consisting of the protein, lipid and glycoprotein components of the mucus, was lyophilised and weighed. Mucus output was calculated by multiplying the concentration of nondialysable material in the sample of gastric juice by the corrected volume of the juice produced in the basal period or in the 90 minutes after pentagastrin. The mucus output in one patient with duodenal ulcer was not measured. The corrected and aspirated gastric volumes were compatible. Saliva, or reflux from the duodenum could not, therefore, be significant sources of error in these determinations.

\section{STATISTICAL ANALYSIS}

The differences in measurements before and after De-Nol were calculated as mean percentage change and compared non-parametrically by Wilcoxon's matched pairs signed ranks test.

\section{Results}

\section{ENDOSCOPY}

After four weeks treatment with De-Nol each of the seven duodenal ulcers, and all but one of the gastric ulcers had healed.

GASTRIC SECRETION (Fig. 1)

After De-Nol there were slight and insignificant changes in corrected volumes during basal and pentagastrin periods in patients with duodenal $(-16 \%,-8 \%)$ and with gastric ulcer $(-10 \%$, $+2 \%)$.

GASTRIC ACID OUTPUT (Fig. 2)

After De-Nol there were slight and insignificant decreases in corrected acid output during basal and pentagastrin periods in patients with duodenal $(-16 \%,-3 \%)$ and with gastric ulcer $(-15 \%$, $-6 \%)$. Similar falls were noted when the data were expressed in terms of primary parietal component as Hobsley's peak $\mathrm{V}_{\mathrm{G}}$ (duodenal ulcer $-14 \%$, gastric ulcer $-4 \%$ ). 

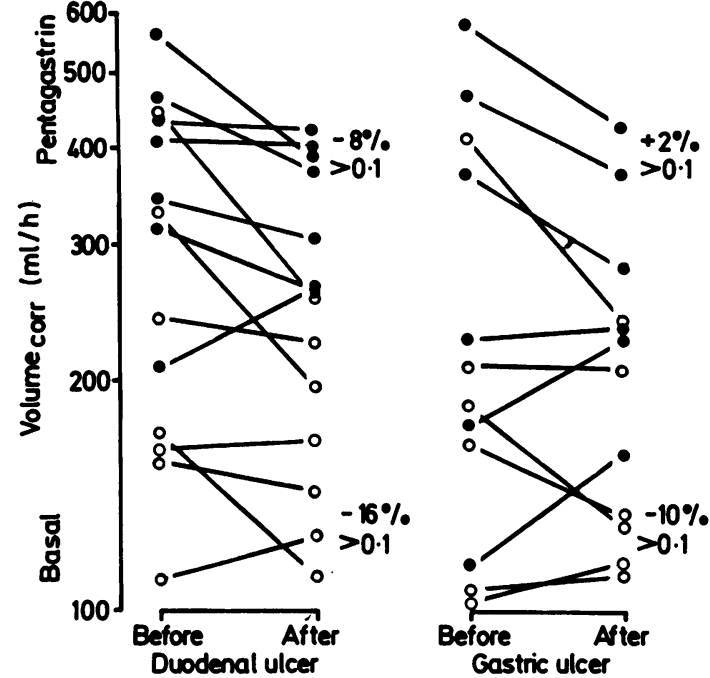

Fig. 1 Corrected gastric juice volume before and after colloidal bismuth subcitrate (De-Nol) in 7 patients with duodenal, and 6 with gastric ulcer. $\bigcirc$ Basal: for all 13 patients mean percentage reduction $=13 \%, p<0 \cdot 1$. - Pentagastrin stimulated: for all 13 patients mean percentage reduction $=3 \%, p>0 \cdot 1$.

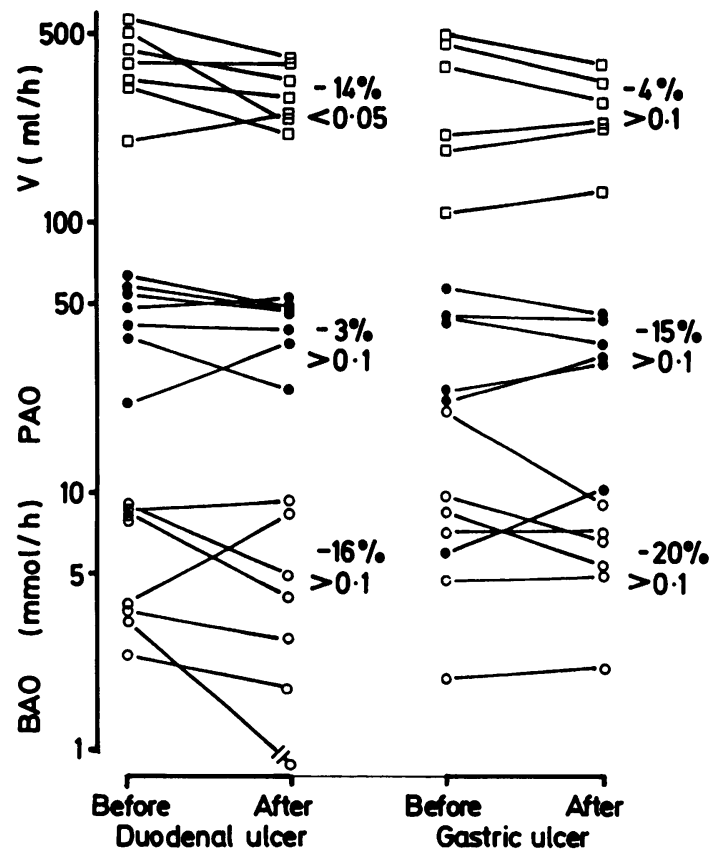

Fig. 2 Gastric acid outputs. $\square$ Basal: for all 13 patients mean percentage reduction $=9 \%, p>0 \cdot 1$. The value below the discontinuity is $0.02 \mathrm{mmol} / \mathrm{h}$. Pentagastrin stimulated: for all 13 patients, mean percentage reduction $=18 \%$, p>0.1. $\bigcirc \mathrm{VG}$ : for all 13 patients, mean percentage reduction $=9 \%, p<0.05$.
PEPSIN

Basal and pentagastrin stimulated pepsin activities fell markedly after De-Nol in patients with duodenal ulcer $(-31 \%,-36 \%)$ but were changed less in those with gastric ulcer $(+4 \%,-19 \%)$. In the whole group of 11 patients with peptic ulcer the decrease in basal pepsin concentration, $-13 \%$, was insignificant, but the decrease in post-pentagastrin pepsin concentration, $-26 \%$ was significant.

Basal and pentagastrin-stimulated pepsin outputs (Figs 3 and 4) were markedly decreased, however,

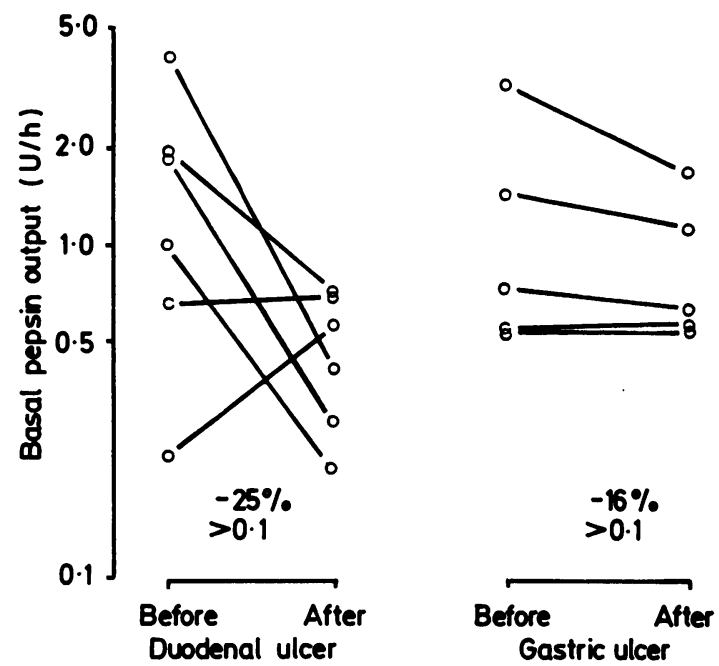

Fig. 3 Basal pepsin output. For all 11 patients mean percentage reduction $=21 \%, p<0 \cdot I$.

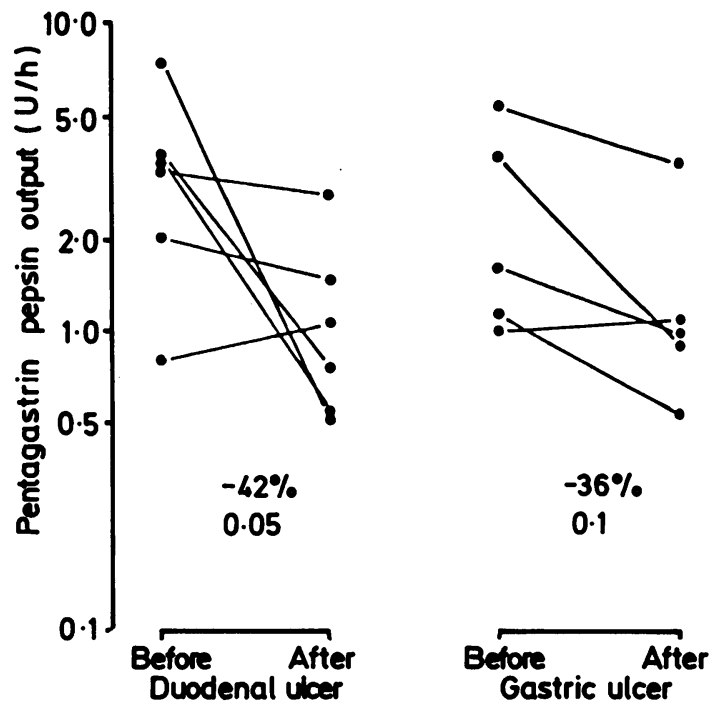

Fig. 4 Pentagastrin stimulated pepsin output. For all 11 patients mean percentage reduction $=39 \%, p<0.01$. 


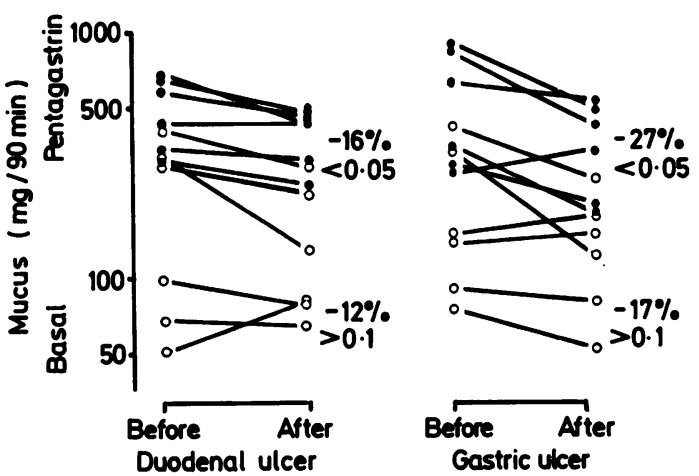

Fig. 5 Mucus output. $\bigcirc$ Basal. For all 12 patients mean percentage reduction $=15 \%, p<0.05 ;$ Pentagastrin stimulated. For all 12 patients mean percentage reduction $=22 \%, p<0 \cdot 01$.

in patients with duodenal $(-25 \%,-42 \%)$ and with gastric ulcer $(-16 \%,-36 \%)$. These decreases were significant after pentagastrin in patients with duodenal ulcer and in the whole group of 11 patients.

MUCUs (Fig. 5)

There were slight decreases after De-Nol in basal output of mucus in patients with duodenal and with gastric ulcer. Pentagastrin stimulated mucus output was, however, significantly inhibited in patients with duodenal $(-16 \%)$ and with gastric ulcer $(-27 \%)$.

\section{Discussion}

Although there are no published data on the effects of colloidal bismuth subcitrate on gastric secretion in man a liquid concentrate of De-Nol $4 \mathrm{mg} / \mathrm{kg}$ for 28 days did not affect the gastric acid production of rats with gastric fistulae. ${ }^{7}$ De-Nol did, however, show a clear dose dependent antipeptic effect which might have been the result of an inactivation of the pepsin by complexation with the precipitate which De-Nol forms at the low $\mathrm{pH}$ of the stomach.

This effect has also been examined by incubation of De-Nol in different concentrations for 30 minutes with human gastric juice at $\mathrm{pH} 4.0$ with a pepsin concentration of $20 \mathrm{mg} / 100 \mathrm{ml}$. The mean inhibition of proteolytic activity at $\mathrm{pH} 2.0$ produced by a suspension of De-Nol at a concentration of $13.7 \mathrm{mmol} / \mathrm{l}(25 \mathrm{mg} / \mathrm{ml})$ was $29 \%$, and at a concentration of $27.5 \mathrm{mmol} / \mathrm{l}(50 \mathrm{mg} / \mathrm{ml})$ was $39 \%$. These in vitro concentrations would never be achieved in vivo in human gastric juice with therapeutic doses of De-Nol, but might conceivably be reached in the microenvironment of an ulcer crater lined with this bismuth salt. ${ }^{12}$ Similar in vitro inhibition of pepsin by De-Nol (but not by other bismuth preparations) has been reported by Brouwers. $^{13}$

The present studies showed decreases of different size in most of the variables measured. With such multiple measurements there is always the risk of some changes achieving statistical significance merely by chance. Moreover any changes noted after a course of treatment may not be caused by the treatment. Conventionally the effects of sequence and consequence are differentiated by comparing the results of a course of drug treatment with the results after a course of placebo. In a country such as Britain with very low placebo-healing rates of gastric and duodenal ulcer, however, it is ethically unacceptable to treat patients suffering from active symptomatic peptic ulcers with placebo. Comparisons can, however, be made with results in our previous studies of basal and pentagastrin stimulated gastric secretion in patients with peptic ulcer treated with a different mucosal protective agent (carbenoxolone $)^{1415}$ and with an acid inhibitor (omeprazole). ${ }^{16}$

No significant changes were seen after $\mathrm{De}-\mathrm{Nol}$ in basal or pentagastrin stimulated acid output, or in primary parietal component in patients with duodenal or gastric ulcer, so that the therapeutic efficacy of De-Nol in these diseases cannot be mediated by inhibition of acid. Similarly, another mucosal protective ulcer healing drug, carbenoxolone, was shown in this department to be without significant effect on either basal or maximal gastric acid output. ${ }^{14}$ The decline in gastric proteolysis observed after De-Nol was also seen in our studies after carbenoxolone. ${ }^{15}$ There are no data to suggest that diminished acid or pepsin outputs after an ulcer healing drug are because of the healing of the ulcer. We found no significant change in pentagastrin stimulated pepsin output in nine patients with duodenal ulcer, eight of whom had healed after treatment for four weeks with omeprazole 20 or $40 \mathrm{mg}$ daily. ${ }^{16}$ It seems reasonable to suggest that the decline in the proteolytic action of gastric juice observed after treatment with De-Nol, or with carbenoxolone, are caused by the drugs, especially as these changes have been also shown in vitro. ${ }^{12} 13 \quad 15$

The marked drop in pepsin output demonstrated in these studies in patients with peptic ulcer after De-Nol may be relevant for its therapeutic action, irrespective of whether the decrease in proteolysis is due to a primary inhibition of chief cells, or to inactivation of pepsin by complexation. It has been suggested that De-Nol improves mucosal defence by restoring the integrity of the mucus as a barrier to acid-pepsin proteolysis. ${ }^{2}$ Clearly, any such action is unlikely to be caused by quantitative stimulation of 
mucus, because we found significant inhibition of gastric mucus output. The alternative, qualitative change in the mucus, is being sought in further studies.

We are greatly indebted to the late Dr Jacob Schrager who initiated and inspired this study. We are grateful to Sister Leela Francis-Reme and $\mathrm{Mr}$ Kang Li for their help with the secretion tests, and wish to thank Brocades (Great Britain) Limited and the Schrager Trust for their financial support.

\section{References}

1 Tytgat GNJ, Paul ZM, eds. De-Nol in the treatment of peptic ulcer. Scand J Gastroenterol 1982; 17: suppl 80.

2 Bardhan KD. Perspectives in duodenal ulcer Welwyn Garden City: Smith Kline \& French, 1981.

3 Surmont $H$, Dubus $A$. Note sur l'action myxogène de quelques sels de bismuth au niveau de l'estomac. Arch Fr Mal App Dig 1908; 3: 537-9.

4 Surmont H, Dubus A. Recherches expérimentales sur le mode d'action du pansement au bismuth dans les affections de l'estomac. Arch Fr Mal App Dig 1908; 2: 701-12.

5 Hollanders D, Morrissey SM, Mehta J. Mucus secretion in gastric ulcer patients treated with tripotassium dicitrate bismuthate (De-Nol). Br J Clin Pract 1983; 37: 112-4.

6 Moshal MG, Gregory MA, Pillay C, Spitaels JM. Does the duodenal cell ever return to normal? A comparison between treatment with cimetidine and De-Nol. Scand J Gastroenterol 1979; suppl 54: 48-51.
7 Wieriks J, Hespe W, Jaitly KD, Koekkoek PH, Lavy U. Pharmacological properties of colloidal bismuth subcitrate (CBS, DE-NOL (R)). Scand J Gastroenterol 1982; 17: suppl 80, 11-16.

8 Baron JH. Clinical tests of gastric secretion. History, methodology and interpretation. London: Macmillan, 1978: New York: Oxford University Press, 1979.

9 Vatier J, Cheret AM, Bonfils S. Le dosage automatique de l'activité protéolytique du suc gastrique. Biol Gastroenterol 1968; 1: 15-29.

10 Faber RG, Russell RCG, Royston CMS, Whitfield P, Hobsley M. Duodenal reflux during insulin-stimulated secretion. Gut 1974; 15: 880-4.

11 McCloy RF. A basal-insulin-pentagastrin gastric secretion test. Appendix to Baron JH. Clinical tests of gastric secretion. History, methodology and interpretation London: Macmillan, 1978: 212-7.

12 Roberts NB, Taylor WH. Effect of tripotassium dicitrobismuthate (De-Nol) upon individual human pepsins. Clin Sci 1982; 63: 65P.

13 Brouwers JRBJ. Pathofysiologe en Farmacotherapie van peptische afwijkingen. Amsterdam University, Thesis 1981: 126-33

14 Baron JH. Effect of carbenoxolone sodium on human gastric acid secretion. Gut 1977; 18: 721-2.

15 Roberts NB, Walker V, Etherington DJ, Baron JH, McConnell RB, Taylor WH. The action of carbenoxolone on enzymes, with special reference to the pepsins and their secretion. Acta Gastroenterol Belg 1983; 46: 448-58.

16 Thompson JN, Barr JA, Collier N et al. Basal, shamfeed and pentagastrin-stimulated gastric acid, pepsin and electrolytes after omeprazole 20 and $40 \mathrm{mg}$ daily. Gut 1985; 26: 1018-24. 